\title{
Pioglitazone Prevents Tau Oligomerization
}

\section{Tadanori Hamano ${ }^{\mathrm{a}, b^{*}}$, Norimichi Shirafuji ${ }^{\mathrm{a}}$, Chiemi Makino ${ }^{\mathrm{a}}$, Shu-Hui Yen ${ }^{\mathrm{c}}$, Nicholas M. Kanaan $^{\text {d }, \text { Asako Ueno }}{ }^{\text {, }}$, Jinya Suzuki ${ }^{e}$, Masamichi Ikawa a , Akiko Matsunaga a , Osamu Yamamura $^{\mathrm{a}}$, Masaru Kuriyama ${ }^{\mathrm{f}}$, and Yasunari Nakamoto ${ }^{\mathrm{a}}$}

a Second Department of Internal Medicine, Faculty of Medical Sciences, University of Fukui, Fukui, Japan,

b Translational Research Center, University of Fukui, Fukui, Japan

c Department of Neuroscience, Mayo Clinic College Florida, Jacksonville, FL, USA

d Department of Translational Science and Molecular Medicine, College of Human Medicine, Michigan State University, Grand Rapids, MI, USA

e Third Department of Internal Medicine, Faculty of Medical Sciences, University of Fukui, Fukui, Japan

f Brain Attack Ota Memorial Hospital, Fukuyama, Japan

*: hamano@u-fukui.ac.jp (TH) 


\section{ABSTRACT}

Tau aggregation and amyloid $\beta$ protein $(\mathrm{A} \beta)$ deposition are the main causes of Alzheimer's disease (AD). Peroxisome proliferator-activated receptor $\gamma$ (PPAR $\gamma$ ) activation modulates A $\beta$ production. To test whether the PPAR $\gamma$ agonist pioglitazone (PIO) is also effective in preventing tau aggregation in $\mathrm{AD}$, we used a cellular model in which wild-type tau protein (4R0N) is overexpressed (M1C cells) (Hamano et al., 2012) as well as primary neuronal cultures. PIO reduced both phosphorylated and total tau levels, and inactivated glycogen synthase kinase $3 \beta$, a major tau kinase, associated with activation of Akt. In addition, PIO decreased cleaved caspase 3 and C-terminal truncated tau species by caspase, which is expected to decrease tau aggregation. A fractionation study showed that PIO reduced high molecularweight $(120 \mathrm{kDa})$, oligomeric tau species in Tris Insoluble, sarkosyl-soluble fractions. Tau decrease was reversed by adding GW9662, a PPAR $\gamma$ antagonist. Together, our current results support the idea that PPAR $\gamma$ agonists may be useful therapeutic agents for AD.

Key words: tau, Pioglitazone, PPAR $\gamma$, phosphorylation, GSK3 $\beta$, tau oligomer, caspase 


\section{Introduction}

The neuropathological hallmarks of Alzheimer's disease (AD) are senile plaques (SPs), which are composed of amyloid $\beta$ protein (A $\beta$ ), and neurofibrillary tangles (NFTs), which are composed of highly phosphorylated tau protein.

Peroxisome proliferator-activated receptor $\gamma(\operatorname{PPAR} \gamma)$ is a ligand-activated nuclear receptor that plays an important role in human disorders including cancer, atherosclerosis, and inflammation [13]. PPAR $\gamma$ agonists, including pioglitazone (PIO), troglitazone, rosiglitazone, and ciglitazone, are synthetic high-affinity ligands for PPAR $\gamma$. PPAR $\gamma$ agonists are already in clinical use for lowering blood glucose and improving insulin resistance in type 2 diabetes [4].

Many clinical studies have shown that the risk of AD increases 2-fold in patients with diabetes [5]. Insulin signaling defects are associated with increased accumulation of NFTs and SPs in AD [6]. Experimental diabetic animals also show cognitive dysfunction and AD pathology including tau phosphorylation [7].

The microtubule-associated protein tau is the main component of paired helical filaments (PHFs) that form NFTs in AD, as well as the hallmark tau inclusions characteristic of argyrophilic grain disease, corticobasal degeneration, progressive supranuclear palsy, Pick's disease, frontotemporal dementia with parkinsonism linked to chromosome 17, Niemann-Pick disease type $\mathrm{C}$, and chronic traumatic encephalopathy [8-9]. Abnormal phosphorylation of tau by glycogen synthase kinase (GSK)3 $\beta$ [10] or cyclin-dependent kinase 5 (cdk5) [11], which are major tau kinases, is considered to be one way that tau becomes pathogenic leading to its aggregation, disruption of biological functions and ultimately, induction of toxicity. Caspase cleavage of tau protein at the $\mathrm{C}$-terminus also promotes tau aggregation and cell toxicity [12]. Caspase upregulation precedes and leads to formation of PHFs [13].

Recent evidence suggests that PPAR $\gamma$ agonists downregulate A $\beta$ deposition in AD cell culture models [14] and prevent $A \beta$-mediated neuronal degeneration in rat hippocampal neurons [15]. Clinical trials of PIO have already begun in patients with AD and mild cognitive impairment [16].

Troglitazone reduces phosphorylation levels of tau by inducing translocation of the 3'phosphoinositide-dependent protein kinase 1 to the nucleus and reducing the cytosolic phosphorylated form of the mammalian target of rapamycin [17], or by inactivating cdk5 [18]. It was also reported that rosiglitazone attenuates $\mathrm{A} \beta$-mediated tau phosphorylation, but the exact mechanisms were not shown [19]. Hu et al., reported that PIO reduced phosphorylated tau (Ser 199/396) in the rat model via GSK3 $\beta$ inactivation [20]. However, they did not demonstrate whether PIO had an effect on tau aggregation or caspase activation.

We used human neuroblastoma M1C cells from the BE(2)-M17D cell line that overexpress human tau (4R0N) by tetracycline off (TetOff) induction, as well as primary neuronal cultures to test the influences of PIO on tau aggregation including oligomerization. M1C cells show accumulation of oligomeric tau and sarkosyl-insoluble tau aggregates following TetOff induction [21, 22]. 


\section{Materials and Methods}

\subsection{Antibodies and chemicals}

The tau antibodies and the epitopes they detect on tau (4R0N) are illustrated in Fig. 1A. These antibodies are well characterized [13, 21-24]. Tau Oligomeric Complex 1 antibody (TOC1) that selectively recognizes tau dimers and high-ordered oligomers was also used [11, 25, 26]. PIO was a kind gift from Takeda Pharmaceutical Co., Ltd. (Tokyo, Japan).

\subsection{Cell culture}

We seeded M1C cells at 1.5-2 × $10^{6}$ cells/dish in Dulbecco's modified Eagle's medium (DMEM) with $10 \%$ fetal bovine serum, G418 (400 $\mu \mathrm{g} / \mathrm{ml}[25])$, and tetracycline (Tet) $(2 \mu \mathrm{g} / \mathrm{ml})$. Twenty-four hours after seeding, tau was expressed by decreasing the Tet concentration to $1 \mathrm{ng} / \mathrm{ml}$ (TetOff induction) for a total of 5 days [21-24]. M1C cells were treated with PIO or dimethyl sulfoxide (DMSO) during the last $24 \mathrm{~h}$ (Fig. 1B). The final DMSO concentration in the medium was $0.1 \%$ in all experiments. Other cultures were exposed to GW9662 for $2 \mathrm{~h}$ before treatment with PIO.

\subsection{Primary neuronal cell culture}

Primary neuronal cell culture was performed according to previous reports [12, 24]. Briefly, cortical neurons from Slc:ICR mice were isolated on embryonic day 16 and plated on chambered coverglass [24] for immunocytochemistry or in $3.5-\mathrm{cm}$ plastic dishes for western blotting. Primary neurons were cultured in serum-free Neurobasal medium [24] and exposed to $5 \mu \mathrm{M}$ Ara $\mathrm{C}$ to inhibit proliferation of non-neuronal cells [11, 24]. All experiments were performed with pure neuronal cells (>95\% neuronal), as confirmed with anti-NeuN [24] immunocytochemistry.

\subsection{Western blotting and dot blot}

Western blotting was performed as previously described [24]. Dot blot samples were directly spotted onto PVDF membrane at known concentrations across the samples [26]. Both Western and dot blots were blocked in blocking solution [24]. After rinsing with TBS-T, blots were incubated with monoclonal antibodies to Tau5 [24], Tau46 [24], PHF-1 [24], CP13 [24], TauC3 [24], TOC1 (1:2,000; [12, 25, 26]), GAPDH [24], or Bcl-2 (1:1,000; Santa Cruz Biotechnology, Santa Cruz, CA, USA), or polyclonal antibodies to GSK3 $\beta$ [24], pGSK3 $\beta$ [24], cleaved caspase3 [24], pAkt (1:500; 
Cell Signaling), or Akt (1:1,000; Cell Signaling) for $60 \mathrm{~min}$ at RT. After washing, blots were incubated in horseradish peroxidase-conjugated sheep anti-mouse IgG, goat anti-rabbit IgG, or goat anti-mouse IgM for TOC1 antibody, $30 \mathrm{~min}$ at RT. After the final TBS-T wash, immunoreactivity of proteins was visualized with an enhanced Chemiluminescence Prime system [24].

\section{5. mRNA expression}

Quantitative real-time PCR (qPCR) was performed according to our previous report [24]. Briefly, 20 ng cDNA per sample in a $20 \mu \mathrm{l}$ reaction volume was used with the StepOnePlus Realtime PCR System. Calculation of relative gene expression was done with the $\delta C T$ method [27]. All experiments were run in triplicate.

\subsection{Fractionation analysis}

Fractionation analysis was done according to our previous studies [21-24]. Briefly, collected cells were homogenized in Tris buffer with phosphatase and protease inhibitors [24]. The supernatant from centrifugation of lysates at $150,000 \times g$ for $15 \mathrm{~min}$ at $4{ }^{\circ} \mathrm{C}$ was considered the SN1 fraction. Pellets were homogenized in buffer containing $10 \%$ sucrose, $0.8 \mathrm{M} \mathrm{NaCl}, 10 \mathrm{mM}$ Tris/ $\mathrm{HCl}(\mathrm{pH} 7.4), 1 \mathrm{mM}$ EGTA, 2\% sarkosyl, and protease inhibitor cocktail, and centrifuged at $150,000 \times g$ for 15 min to obtain the SN2 fraction (Tris insoluble, sarkosyl soluble) and sarkosyl-insoluble pellet (S/P).

\subsection{Morphological study}

Cells were cultured in 24-well plates, and morphological studies were done with an inverted microscope [24] with or without PIO, as previously reported [24]. Estimation of living cell numbers was done by quantitation of the ATP levels [24].

\subsection{Immunocytochemistry}

Immunocytochemistry was done according to our previous study [24]. Briefly, cells grown on Lab-Tek chambered coverglass were treated with TetOff induction for 5 days. After PIO or vehicle treatment, cells were fixed with $4 \%$ paraformaldehyde/0.1 M phosphate buffer. Cells were washed with phosphate-buffered saline (PBS) and permeabilized with $0.25 \%$ Triton X-100/PBS. After blocking, they were incubated in P44, PHF-1, or CP13 in blocking solution, followed by anti-mouse IgG (Alexa 488 [24]) and anti-rabbit IgG (Alexa 594 [24]) in blocking solution. Immunoreactivity was observed 
with a confocal fluorescence microscope [24].

\section{9. Statistical analysis}

In the figures, all values are the mean \pm SEM. Comparison between two groups was done with the Student's $t$-test, and among more than two groups, multiple comparisons were done with one-way analysis of variance (ANOVA) (IBM SPSS Statistics, version 22, IBM Corp, Armonk, NY, USA), with $\mathrm{p}<0.05$ considered significant.

\section{Results and discussion}

\subsection{PIO decreases total and phosphorylated tau in MIC cells}

Total tau (Tau5, and Tau46) was significantly decreased with 0.01 to $10 \mu \mathrm{M}$ PIO. When cells were treated with $0.1 \mu \mathrm{M}$ PIO, Tau5-positive bands (46-60 kDa) were reduced to $70.1 \pm 9.5 \%$ (mean \pm SEM) of the level in the DMSO control, and Tau46-positive tau bands (50-58 kDa) were reduced to $62.4 \pm 1.0 \%$ of the level in the DMSO control. PIO did not change tau mRNA levels as shown with qPCR (Fig. 1E).

When the cells were treated with $0.1 \mu \mathrm{M}$ PIO, PHF-1-positive bands (52-68 kDa) were reduced to $54.5 \pm 11.2 \%$, and the CP13-positive band was reduced to $34.6 \pm 8.4 \%$ of the levels in the DMSO control (Fig. 3A, B). Importantly, PIO decreased the ratio of phosphorylated versus total tau (PHF-1/Tau5: $76.7 \pm 3.8 \%$ ) or (CP13/Tau5: $46.3 \pm 12.3 \%)$ (Fig. 2C).

By immunofluorescence labeling of M1C cells, PIO-treated cultures displayed more cells with no or very little immunoreactivity for phosphorylated tau (CP13), but total tau (P44)-positive cells were only slightly reduced by PIO (Fig. 2D). Ser9-phosphorylated GSK3 $\beta$ was upregulated by PIO (Fig. 2E), implying that GSK3 $\beta$ was inactivated. Phosphorylation levels of Akt were also upregulated by PIO (Fig. 2F).

\subsection{PIO decreases endogenous tau in primary cultured neurons}

Primary cortical neurons were exposed to PIO for $24 \mathrm{~h}$ to test the influence of PIO on endogenous tau. PIO $(0.5 \mu \mathrm{M})$ reduced total tau (Tau5) and phosphorylated tau (PHF-1 and CP13), as shown with western blot analysis (Supple Fig. 1A). Importantly, PIO decreased the ratio of phosphorylated versus total tau (PHF-1/Tau5: $71.6 \pm 10.7 \%$ ) or (CP13/Tau5: $67.0 \pm 19.8 \%$ ) as shown with western blotting (Supple Fig. 1B). Decrease in phosphorylated tau (CP13) was also detected with 
immunocytochemistry of cells treated with $1 \mu \mathrm{M}$ PIO (Fig. 2G).

3.3. PIO decreases soluble and sarkosyl-insoluble tau, including high molecular-weight tau species (120 kDa) in M1C cells

PIO-treated cells contained markedly lower amounts of tau in the all fractions ( $\mathrm{S} / \mathrm{P}, \mathrm{SN} 2$, and SN1 [data not shown]) than the DMSO control by fractionation study. Importantly, high molecularweight (120 kDa) phosphorylated tau (CP13) identified in sarkosyl-soluble (SN2) fractions was decreased by PIO [24] (Fig. 3). Dot blot analysis in lysates (Fig. 3B) and immunocytochemical study (Fig. 3C) by using tau oligomer specific TOC1 antibody [27, 28] detected reduction of oligomeric tau.

\subsection{PIO protects against tau-induced cell death}

Tau or phosphorylated tau overexpression has been shown to decrease neuronal cell viability [28-30], we next examined whether PIO rescued cells from tau-induced death. First, we examined the influence of PIO on the morphology of M1C cells overexpressing tau (Fig. 4A). No obvious differences were seen between cultures treated with vehicle or PIO at concentrations of 0.01 to $10 \mu \mathrm{M}$. As shown in Fig. 4B (comparing NI to 0), tau overexpression moderately decreased cell viability as shown by the ATP viability assay. Instead, cell viability was modestly, but significantly increased with $0.01 \mu \mathrm{M}, 10$ $\mu \mathrm{M}$ and $100 \mu \mathrm{M}$ PIO. However, at concentrations higher than $100 \mu \mathrm{M}$, PIO became cytotoxic. The $\mathrm{LD}_{50}$ value obtained from the ATP assay was $9.28 \mathrm{mM}$ PIO for M1C cells.

\subsection{Effect of PIO on cell survival-relevant proteins}

PIO increased the anti-apoptotic Bcl-2 protein (Fig. 4C) and decreased cleaved caspase3 (Fig. 4D), suggesting that PIO has anti-apoptotic actions. With the reduction in caspase3 (Fig. 4D), TauC3positive, a C-terminal caspase-cleaved tau product, was also decreased by PIO (Fig. 4E).

\subsection{The reduction in tau by PIO is reversed by the addition of a PPARy antagonist}

M1C cells with tau expression were co-treated with $0.1 \mu \mathrm{M}$ PIO and GW9662 as a selective PPAR $\gamma$ antagonist to determine whether the decrease in tau by PIO was caused by activation of PPAR $\gamma$ itself. GW9662 reversed the decrease in total and phosphorylated tau by PIO (Fig. 4F). The number of live cells was slightly increased by PIO; however, in both PIO- and GW9662-treated cells, the living cell number was decreased compared with only PIO treated cells as demonstrated with the ATP assay.

We demonstrated that PIO significantly decreased tau in both M1C neuroblastoma cells (Fig. 
1) and primary neurons (Fig 2G, Supple 1). In addition, PIO decreased the amount of phosphorylated tau (CP13 and PHF-1) (Figs 2, 3, 4). Abnormal tau phosphorylation affects its conformation and facilitates tau assembly, leading to the formation of PHFs and NFTs [10].

PIO reduced the levels of high molecular-weight tau in tris insoluble, sarkosyl-soluble (SN2) fractions (Fig. 3B). The apparent $120 \mathrm{kDa}$, high molecular-weight tau species are likely oligomeric multimers that correspond to previously described tau dimers $[22,26]$. Oligomeric tau likely plays a key role in $\mathrm{AD}$ progression [25, 26]. It is present in early stages of neuronal cytopathology in AD and is closely correlated with abnormal tau phosphorylation at sites that can negatively affect microtubule binding. Injection of tau oligomers into the brain facilitates aggregation of endogenous tau, leading to the propagation of tau pathology, like prion [32]. Dot blot analysis showed that PIO reduced TOC1 positive oligomeric tau. It was reported that TOC1 preferentially labels pre-fibrillar tau multimers (e.g., dimers and oligomer) in the early stages of tau pathology formation in AD [26].

The PPAR $\gamma$ antagonist GW9662 reversed the effects of PIO on tau aggregation and cell viability (Fig 4F), suggesting an important role for PPAR $\gamma$ activation in tau self-interactions. Regarding tau phosphorylation, GSK3 $\beta$ was inactivated. GSK3 $\beta$ can phosphorylate tau at Ser396/404 and other sites [34]. Here, we show that PIO-treated cells contain more active Akt than untreated cells [35]. Thus, Akt-mediated inhibition of GSK3 $\beta$ may contribute, at least in part, to GSK3 $\beta$ inactivation.

With the ATP viability assay, PIO at concentrations $\leq 100 \mu \mathrm{M}$ did not exert cytotoxic effects. We also showed that induced tau expression led to decreased cell viability, an effect that was reversed by moderate concentrations (up to $100 \mu \mathrm{M}$ ) of PIO (Fig. 4). This protective effect may be due to activation of Akt and the influence of PIO on the level and activity of Bcl-2 [36] and caspases (Fig. 4C, D). Our studies showed less TauC3-positive tau in PIO-treated cultures (Fig. 4E). Of note, C-terminal truncated tau protein is more susceptible to oligomerization than intact tau $[12,13]$.

Our results indicate that PIO attenuated tau aggregation by enhancing tau turnover, decreasing phosphorylated tau, and reducing C-terminal truncated tau species, which were associated with GSK3 $\beta$ and caspase 3 inactivation. This is the first demonstration that PIO reduces oligomeric tau, as detected by TOC1 (Fig. 3C, D).

\section{Competing Financial Disclosures}

All authors declared that they have no competing financial interests.

\section{Acknowledgements}

We thank Dr. Li-wen Ko, for developing the M1C cell model, Tania Gendron (Department of Neuroscience, Mayo Clinic Jacksonville), for her critical reading of this manuscript, as well as Aiko Ishida, and Haruna Kusaka for their excellent technical assistance. We thank Takeda Pharmaceutical 
Co., Ltd., for providing PIO, V. M. Lee (University of Pennsylvania, PA, USA) for giving the Tau46 antibody, and Dr. Peter Davies (Albert Einstein University, Bronx, NY, USA) for the generous gift of PHF-1 and CP13 antibodies. A part of this study was supported by the JSPS KAKEN Grant Number JP (25460893, 40529319, 16K09235), JST (AS242Z03676Q), and research grant from University of Fukui.

\section{References}

[1] I. Issemann, S. Green, Activation of a member of the steroid hormone receptor superfamily by peroxisome proliferators. Nature 347(1990) 645-650.

[2] W. Wahli, O. Braissant, B. Desvergne, Peroxisome proliferator activated receptors: transcriptional regulators of adipogenesis, lipid metabolism and more.... Chem. Biol. 2 (1995) 261-266.

[3] K. Fuenzalida, R. Quintanilla, P. Ramos, D. Piderit, R.A. Fuentealba, G. Martinez, N.C. Inestrosa, M.Bronfman, Peroxisome proliferator-activated receptor gamma up-regulates the Bcl-2 antiapoptotic protein in neurons and induces mitochondrial stabilization and protection against oxidative stress and apoptosis. J. Biol. Chem. 282 (2007) 37006-37015.

[4] J.M. Lehmann, L.B. Moore, T.A. Smith-Oliver, W.O. Wilkison, T.M. Willson, S.A. Kliewer, An antidiabetic thiazolidinedione is a high affinity ligand for peroxisome proliferator-activated receptor gamma (PPAR gamma). J. Biol. Chem. 270 (1995) 12953-12956.

[5] A. Ott, R.P. Stolk, F. van Harskamp, H.A. Pols, A. Hofman, M.M. Breteler, Diabetes mellitus and the risk of dementia: The Rotterdam Study. Neurology 53(1999) 1937-1942.

[6] A.M. Moloney, R.J. Griffin, S. Timmons, R, O'Connor, R. Ravid, C. O'Neill, Defects in IGF-1 receptor, insulin receptor and IRS-1/2 in Alzheimer's disease indicate possible resistance to IGF-1 and insulin signaling. Neurobiol. Aging 31 (2010) 224-243.

[7] B.J. Clodfelder-Miller, A.A. Zmijewska, G.V. Johnson, R.S. Jope, Tau is hyperphosphorylated at multiple sites in mouse brain in vivo after streptozotocin-induced insulin deficiency. Diabetes 55 (2006) 3320-3325.

[8] V.M. Lee, M. Goedert, J.Q. Trojanowski, Neurodegenerative tauopathies. Annu. Rev. Neurosci. 24 (2001)1121-1159.

[9] N.M. Kanaan, K. Cox, V.E. Alvarez, T.D. Stein, S. Poncil, A.C. McKee, Characterization of Early Pathological Tau Conformations and Phosphorylation in Chronic Traumatic Encephalopathy. J. Neuropathol. Exp. Neurol.75 (2016) 19-34.

[10] A.C. Alonso, I. Grundke-Iqbal, K. Iqbal, Alzheimer's disease hyperphosphorylated tau sequesters normal tau into tangles of filaments and disassembles microtubules. Nat. Med. 2 (1996) 783787.

[11] P. Han, F. Dou, F. Li, X. Zhang, Y.W. Zhang, H. Zheng, S.A. Lipton, H. Xu, F.F. Liao, Suppression of cyclin-dependent kinase 5 activation by amyloid precursor protein: a novel excitoprotective mechanism involving modulation of tau phosphorylation. J. Neurosci. 25 
(2005) 11542-11552.

[12] T.C. Gamblin, F. Chen, A. Zambrano, A. Abraha, S. Lagalwar, A.L. Guillozet, M. Lu, Y. Fu, F. Garcia-Sierra, N. LaPointe, R. Miller, R.W. Berry, L.I. Binder, V.L. Cryns, Caspase cleavage of tau: linking amyloid and neurofibrillary tangles in Alzheimer's disease. Proc. Natl. Acad. Sci. U. S. A. 100 (2003) 10032-10037.

[13] A. de Calignon, L.M. Fox, R. Pitstick, G.A. Carlson, B.J. Bacskai, T.L. Spires-Jones, et al. Caspase activation precedes and leads to tangles. Nature 464 (2010) 1201-1204.

[14] I.E. Camacho, L. Serneels, K. Spittaels, P. Merchiers, D. Dominguez, B. De Strooper, Peroxisome-proliferator-activated receptor gamma induces a clearance mechanism for the amyloid-beta peptide. J. Neurosci. 24 (2004)10908-10917.

[15] D.A. Costello, D.M. O'Leary, C.E. Herron, Agonists of peroxisome proliferator-activated receptor-gamma attenuate the Abeta-mediated impairment of LTP in the hippocampus in vitro. Neuropharmacology 49 (2005) 359-366.

[16] A.D. Roses, A.M. Saunders, M.W. Lutz, N. Zhang, A.R. Hariri, K.E. Asin, D.G. Crenshaw,

K. Budur, D.K. Burns, S.K. Brannan, New applications of disease genetics and pharmacogenetics to drug development. Curr. Opin. Pharmacol. 14 (2014) 81-89.

[17] C. d'Abramo, R. Ricciarelli, M.A. Pronzato, P. Davies, Troglitazone, a peroxisome proliferator activated- $\gamma$ agonist, decreases tau phosphorylation in CHO tau 4R cells. J. Neurochem. 98 (2006) 1068-1077.

[18] D.H. Cho, E.J. Lee, K.J. Kwon, C.Y. Shin, K.H. Song, J.H. Park, I. Jo, S.H.Han, Troglitazone, a thiazolidinedione, decreases tau phosphorylation through the inhibition of cyclin-dependent kinase 5 activity in SH-SY5Y neuroblastoma cells and primary neurons. J. Neurochem. 126 (2013) 685-695.

[19] T.Tokutake, K. Kasuga, R. Yajima, Y. Sekine, T. Tezuka, M. Nishizawa, et al. Hyperphosphorylation of Tau induced by naturally secreted amyloid- $\beta$ at nanomolar concentrations is modulated by insulin-dependent Akt-GSK3 $\beta$ signaling pathway. J. Biol. Chem. 287 (2012) 35222-35233.

[20] S.H. Hu, T. Jiang, S.S. Yang, Y. Yang, PIO ameliorates intracerebralinsulin resistance and tauprotein hyperphosphorylation in rats with type 2 diabetes. Exp. Clin. Endocrinol. Diabetes 121 (2013) 220-224.

[21] L.W. Ko, Rush T, Sahara N, Kersh JS, Easson C, Deture M, W.L. Lin, Y.D. Connor, SH. Yen, Assembly of filamentous tau aggregates in human neuronal cells. J. Alzheimers Dis. 6 (2004) 605-622.

[22] T. Hamano, T.F. Gendron, E. Causevic, S.H. Yen, W.L. Lin, C. Isidoro, M. Deture, L.W.Ko, Autophagic-lysosomal perturbation enhances tau aggregation in transfectants with induced wildtype tau expression. Eur. J. Neurosci. 27(2008) 1119-1130. 
[23] T. Hamano, T.F. Gendron, L.W. Ko, S.H. Yen, Concentration-dependent effects of proteasomal inhibition on tau processing in a cellular model of tauopathy. Int. J. Clin. Exp. Pathol. 2 (2009) 561-573.

[24] T. Hamano, S.H. Yen, T. Gendron, L.W. Ko, M. Kuriyama, Pitavastatin decreases tau levels via the inactivation of Rho/ROCK. Neurobiol. Aging 33 (2012) 2306-2320.

[25] K.R. Patterson, C. Remmers, Y. Fu, S. Brooker, N.M. Kanaan, L. Vana, S. Ward, J.F. Reyes, K. Philibert, M.J. Glucksman, L.I.Binder, Characterization of prefibrillar Tau oligomers in vitro and in Alzheimer disease. J. Biol. Chem. 286 (2011) 23063-23076.

[26] S.M. Ward, D.S. Himmelstein, Y. Ren, Y. Fu, X.W. Yu, K. Roberts, L.I. Binder, N. Sahara, TOC1: a valuable tool in assessing disease progression in the rTg4510 mouse model of tauopathy. Neurobiol. Dis. 67 (2014) 37-48.

[28] C. Andorfer, C.M. Acker, Y. Kress, P.R. Hof, K. Duff, P. Davies, Cell-cycle reentry and cell death in transgenic mice expressing nonmutant human tau isoforms. J. Neurosci. 25 (2005) 5446-5454.

[29] E. Thies, E.M. Mandelkow, Missorting of tau in neurons causes degeneration of Synapses that can be rescued by the kinase MARK2/Par-1. J Neurosci. 27 (2007) 2896-2907.

[30] T. Fath, J. Eidenmüller, R. Brandt, Tau-mediated cytotoxicity in a pseudohyperphosphorylation model of Alzheimer's disease. J. Neurosci. 22 (2002) 9733-9741.

[31] Meraz-Ríos MA, Lira-De León KI, Campos-Peña V, De Anda-Hernández MA, Mena-López R (2010) Tau oligomers and aggregation in Alzheimer's disease. J Neurochem 112: 1353-1367.

[32] B.B. Holmes, M.I. Diamond, Prion-like Properties of tau protein: The importance of extracellular tau as a therapeutic target. J. Biol. Chem. 289 (2014) 19855-19861.

[33] A. Abraha, N. Ghoshal, T.C. Gamblin, V. Cryns, R.W. Berry, J. Kuret, LI.Binder, C-terminal inhibition of tau assembly in vitro and in Alzheimer's disease. J. Cell Sci. 113 (2000) 3737-3745.

[34] A. Cavallini, S. Brewerton, A. Bell, S. Sargent, S. Glover, C. Hardy, R. Moore, J. Calley, D. Ramachandran, M. Poidinger, E. Karran, P. Davies, M. Hutton, P. Szekeres, S.Bose, An unbiased approach to identifying tau kinases that phosphorylate tau at sites associated with Alzheimer disease. J. Biol. Chem. 288 (2013) 23331-23347.

[35] D.A. Cross, D.R. Alessi, P. Cohen, M. Andjelkovich, B.A. Hemmings, Inhibition of glycogen synthase kinase-3 by insulin mediated by protein kinase B. Nature 378 (1995) 785-789.

[36] J.S. Wu, T.N. Lin, K.K. Wu, Rosiglitazone and PPAR-gamma overexpression protect mitochondrial membrane potential and prevent apoptosis by upregulating anti-apoptotic Bcl-2 family proteins. J. Cell Physiol. 220 (2009) 58-71. 


\section{FIGURE LEGENDS}

Fig. 1. Pioglitazone (PIO) decreased total tau. Schematic illustration of tau (4R0N) and tau antibodies A. and schedule of tetracycline off (TetOff) induction B. With $1 \mathrm{ng} / \mathrm{ml}$ tetracycline, TetOff induction was started on day 0 . PIO treatment was performed during the last $24 \mathrm{~h}$ of the 5 total days of TetOff induction. GAPDH was used to verify the same loading amount among lanes. Total tau (Tau5) was reduced in a dose-dependent manner by 0.01 to $1 \mu \mathrm{M}$ PIO treatment. However, with $10 \mu \mathrm{M}$ PIO, a slight increase in total tau was observed compared with tau levels in cells exposed to $1 \mu \mathrm{M}$ PIO (C). Tau46 (recognizes the C-terminus of tau)-positive bands also decreased (D). Data are the relative levels compared to the control (1). $\mathrm{N}=5, \mathrm{NI}=$ non-induced cells without PIO, Bar: \pm standard error (SEM), PIO did not change tau mRNA levels, as shown with quantitative real-time PCR (qPCR) (E). Data are the relative change compared with the control (1). $\mathrm{N}=6$, Bar: \pm SEM, NS, not significant, $*^{*} \mathrm{p}<0.01$, compared with 0 group, ${ }^{*} \mathrm{p}<0.05$, compared with 0 group.

Fig. 2. Phosphorylated tau was reduced by pioglitazone (PIO). Phosphorylated tau (PHF-1 (A) and CP13) (B) was also reduced by PIO. N = 5, NI = non-induced cells without PIO, 0: cells treated with DMSO. Bar: \pm SEM, $* \mathrm{p}<0.05, * * \mathrm{p}<0.01$. C. The ratio of phosphorylated tau to total tau was reduced by PIO (PHF-1/Tau5, CP13/Tau5). Data are the relative decrease compared with the DMSO control (N $=5$ ), $\mathrm{p}<0.05$ versus control (without PIO). D. Immunocytochemistry showed significantly reduced immunoreactivity of phosphorylated tau (CP13) with PIO $(0.1 \mu \mathrm{M})$. CP13-positive cell numbers were determined in five visual fields. Bar: \pm SEM, ${ }^{*} p<0.05$. E. PIO increased glycogen synthase kinase $3 \beta$ (GSK3 $\beta$ ) phosphorylation levels at Ser9. $\mathrm{N}=5$, Bar: \pm SEM, $* * p<0.01$. F. PIO increased phosphorylation levels of Akt. *p < 0.05, compared with the 0 group. G. Immunocytochemistry showed a reduction in phosphorylated endogenous tau $(\mathrm{CP} 13)$ in mouse neuronal culture with $1 \mu \mathrm{M}$ PIO $(\mathbf{C})$. Bar: $10 \mu \mathrm{m}$.

Fig. 3. Pioglitazone (PIO) reduced oligomeric tau. Fractionation analysis showed that total tau (Tau5), phosphorylated tau protein (CP13) and caspase cleaved tau (TauC3) were decreased in tris insoluble, sarkosyl-insoluble (S/P) and sarkosyl-soluble fractions (SN2) by PIO. In non-reducing conditions, high molecular-weight oligomeric tau $(120 \mathrm{kDa})$ in the SN2 fractions was also decreased by PIO (arrow) (CP13). -: PIO (-), +: $0.1 \mu \mathrm{M}$ PIO. Data are the relative decrease compared with the control (1). $\mathrm{N}=$ 5, Bar: \pm SEM, $* \mathrm{p}<0.05, * * \mathrm{p}<0.01$. The TOC1 antibody, which specifically identifies oligomeric tau, detected a reduction of tau oligomers in PIO treated lysates compared with control cells by dot blot analysis. -: PIO (-), +: $0.1 \mu \mathrm{M}$ PIO. $\mathrm{N}=5$, Bar: \pm SEM, ${ }^{*} \mathrm{p}<0.05$ (A). Immunocytochemical study also detected reduction of oligomeric tau by PIO. DMSO: PIO (-), PIO: $0.1 \mu \mathrm{M}$ PIO (B).

Fig. 4. Up to $100 \mu$ M Pioglitazone (PIO) did not show cytotoxic effects, and tau reduction by PIO 
was reversed by a PPAR $\gamma$ antagonist. A. Morphological changes in M1C cells with PIO were examined with phase-contrast microscopy. Even $10 \mu \mathrm{M}$ PIO did not induce any alterations in cell morphology that suggested apoptosis. Bar: $20 \mu \mathrm{m}$. B. The effects of PIO on M1C cell survival following TetOff induction of tau expression was examined with the ATP assay. Tau overexpression caused a decrease (up to 20\%) in cell viability (comparing 0 to NI). Low to moderate concentrations of PIO (0.01-100 $\mu \mathrm{M})$ provided moderate rescue effects. However, concentrations higher than $100 \mu \mathrm{M}$ PIO were cytotoxic. The $\mathrm{LD}_{50}$ value obtained from the ATP assay was 9,280 $\mu \mathrm{M}$ PIO for M1C cells. Data are the relative change compared with the control (1). NI: non-induced cells without PIO, N=4, Bar: \pm SEM, ${ }^{*} \mathrm{p}<0.05,{ }^{* *} \mathrm{p}<0.01$, versus vehicle control, as determined with ANOVA. Anti-apoptotic protein, $\mathrm{Bcl}-2$ was increased by PIO $(\mathbf{C})$, especially when cells were treated with $0.1 \mu \mathrm{M}$ PIO. With the decrease in cleaved caspase 3 (D), caspase-cleaved tau (TauC3) was also decreased by PIO (E). N=4, Bar: \pm SEM, $* \mathrm{p}<0.05, * * \mathrm{p}<0.01$, versus vehicle control. The decrease in total and phosphorylated tau by PIO was reversed by adding GW9662, a selective PPAR $\gamma$ antagonist. PIO: $0.1 \mu \mathrm{M}$ PIO, GW9662: $10 \mu \mathrm{M}$ GW9662, N= Bar: \pm SEM, NS: not significant, ${ }^{*} \mathrm{p}<0.05$, compared with vehicle control (F). The ATP assay showed that the cell number slightly increased by PIO; however, PIO and GW9662 co-treatment decreased the living cell number compared with PIO treated cells. N=4, *p < $0.05(\mathbf{G})$.

Supple 1. Primary neurons were exposed to PIO for $24 \mathrm{~h}$. PIO $(0.5 \mu \mathrm{M})$ reduced total endogenous tau and phosphorylated endogenous tau (PHF-1 and CP13) as detected with western blot analysis (A). N=5, Bar: \pm SEM, $* \mathrm{p}<0.05,{ }^{*} \mathrm{p}<0.01$, versus DMSO control. Importantly, PIO decreased the ratio of phosphorylated versus total tau (PHF-1/Tau5: $71.6 \pm 10.7 \%)$ or (CP13/Tau5: $67.0 \pm 19.8 \%)(B)$. 
Fig. 1.

A

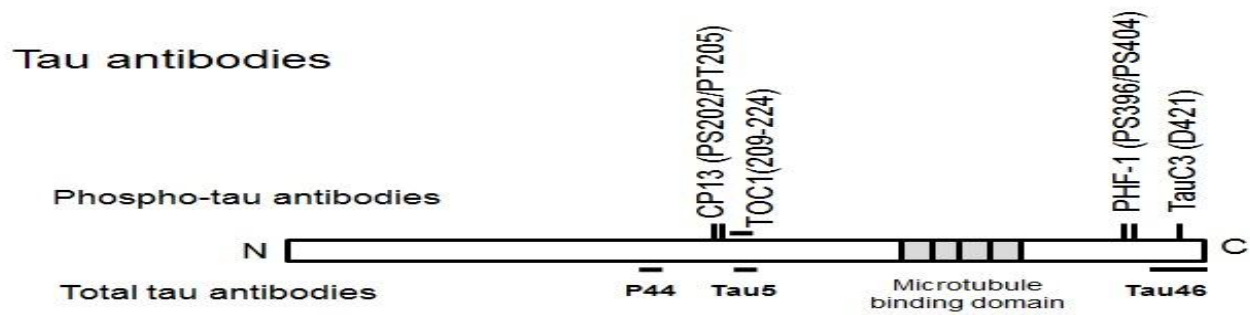

B Schedule of TetOff induction of tau protein

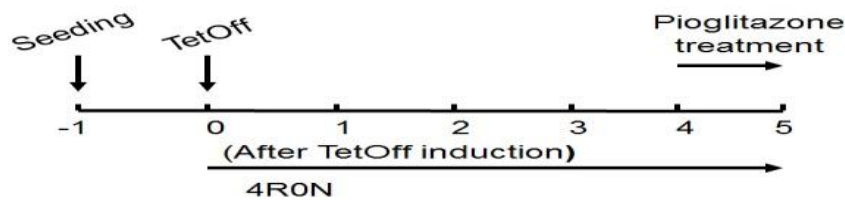

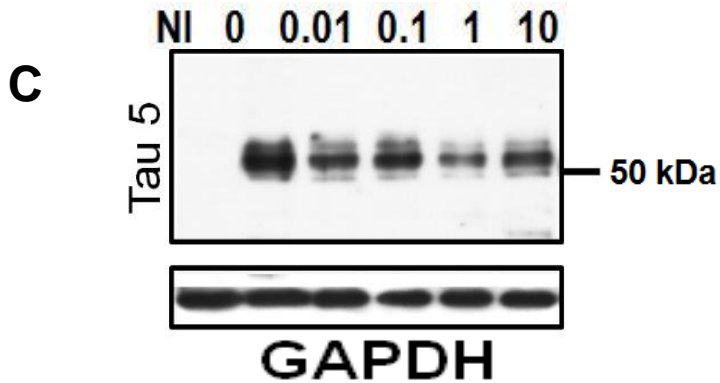

Tau5

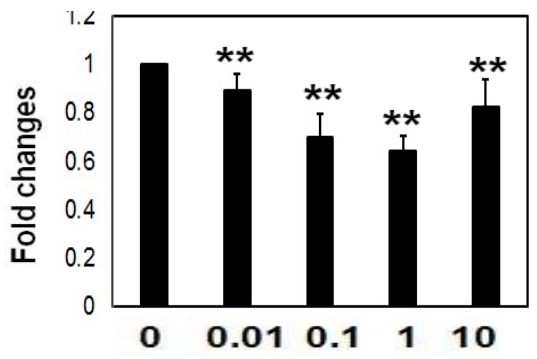

E

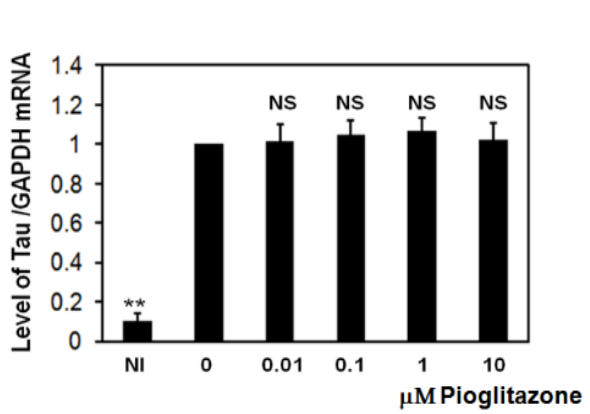

E

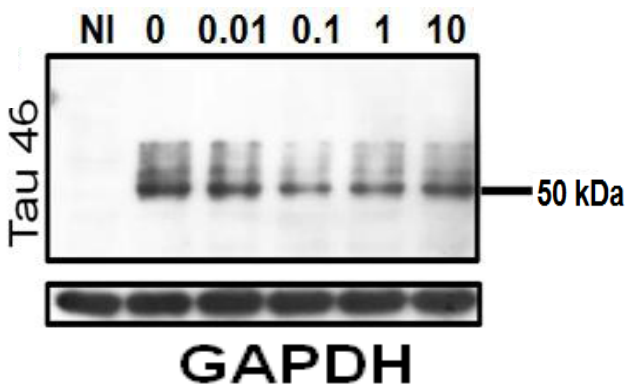

Tau46

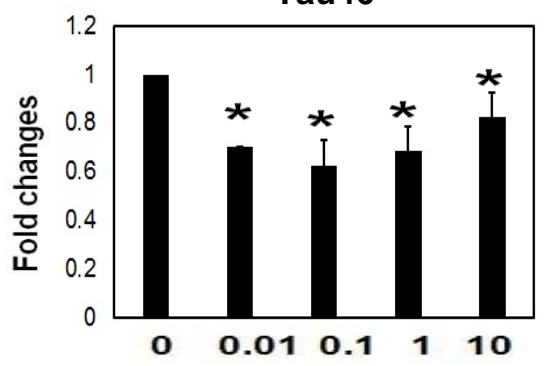


Fig. 2.

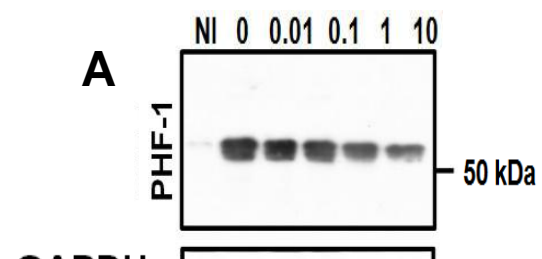

GAPDH

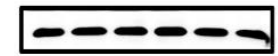

PHF-1

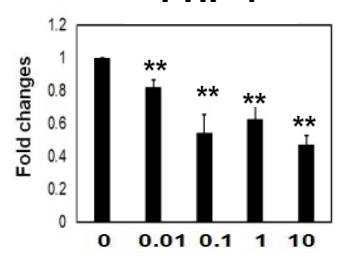

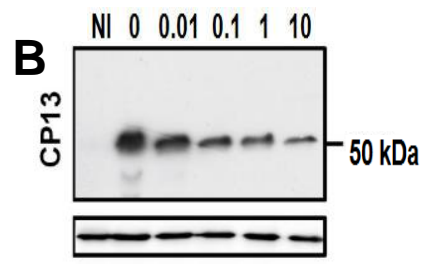

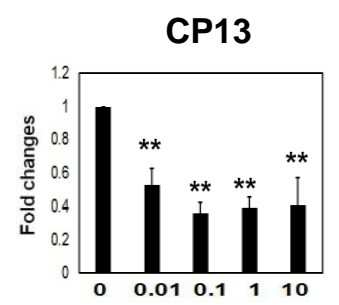

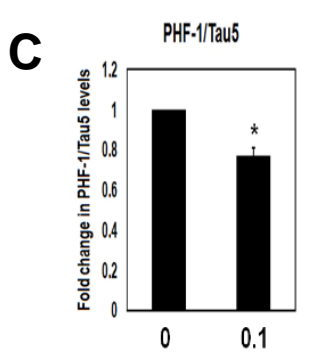

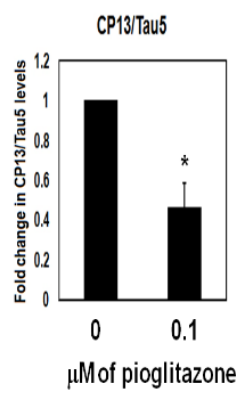

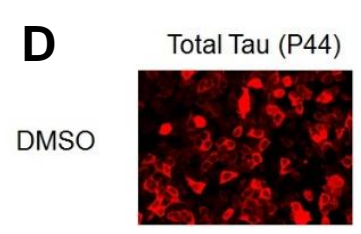
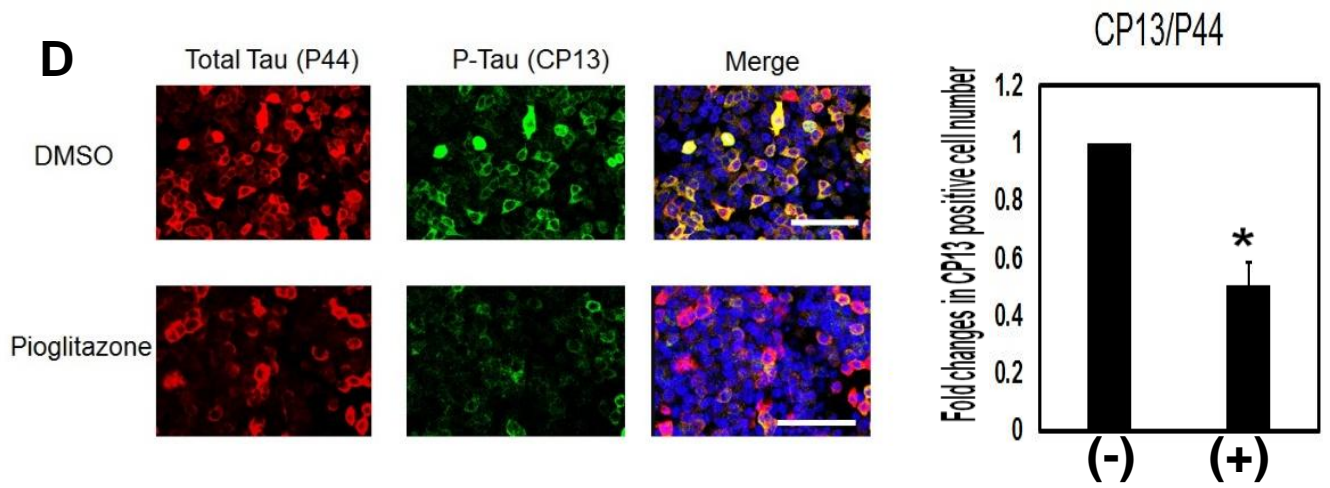

E
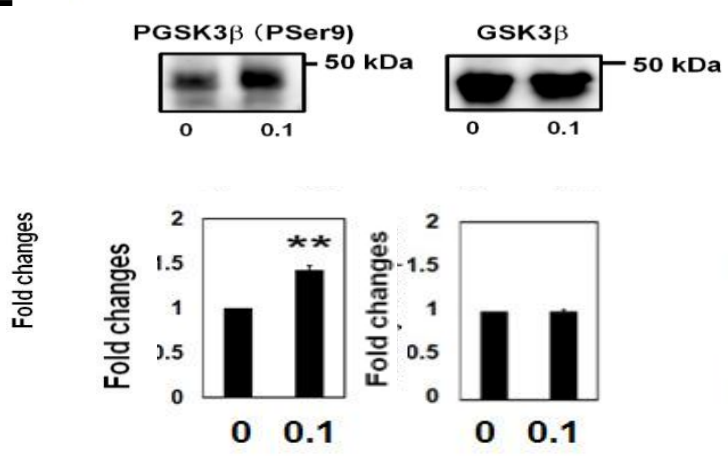

F
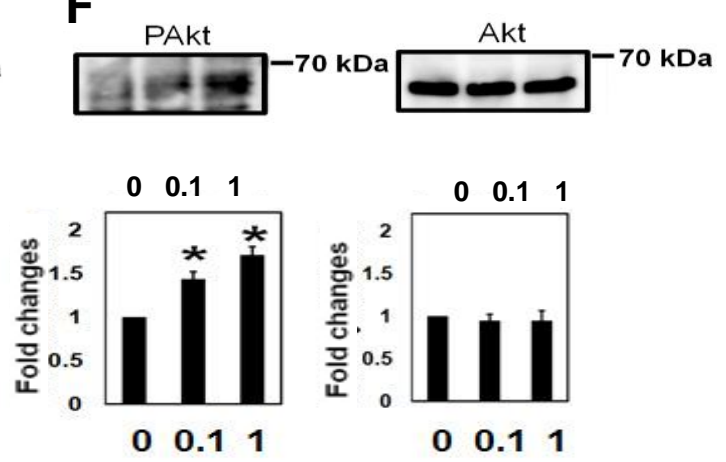

P-Tau (CP13)

G

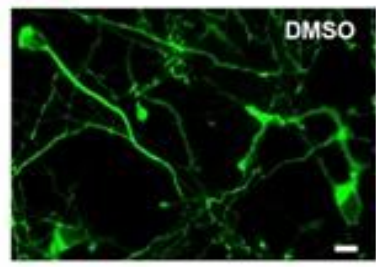

pioglitazone 
Fig. 3.

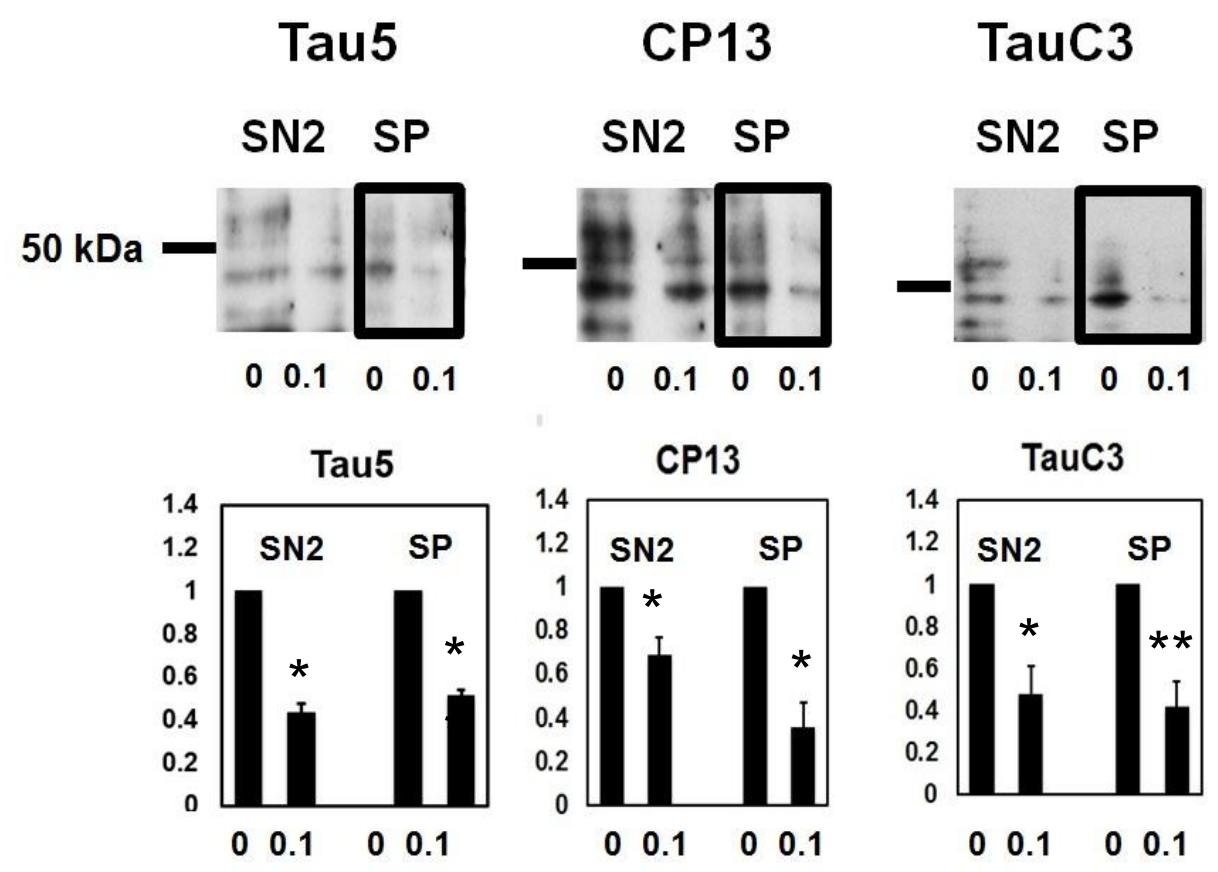

B

CP13 SN2 (- $\beta M E)$

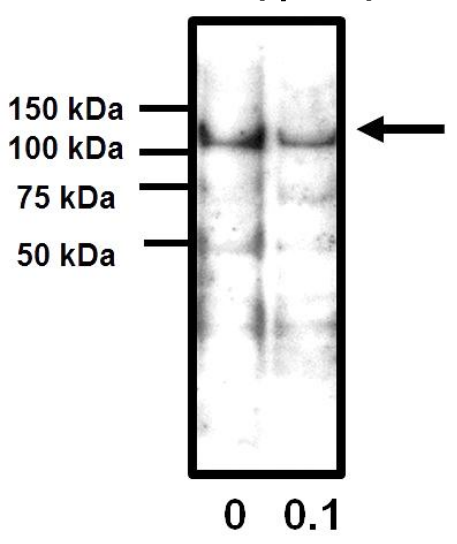

TOC1

C

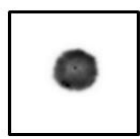

$-$

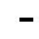

TOC-1

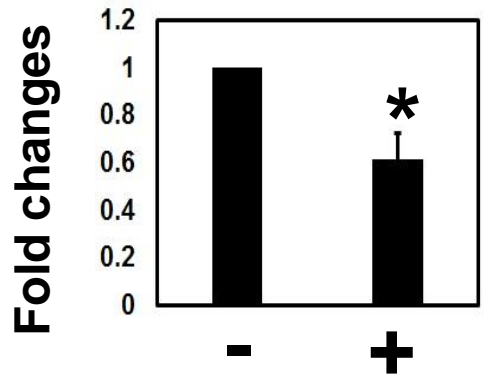

$120 \mathrm{kDa}$ tau

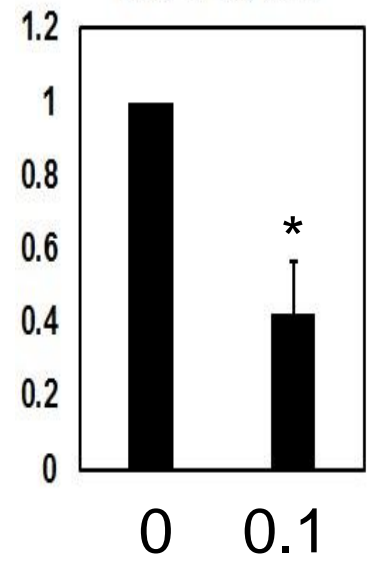

D

DMSO

Total Tau (P44) Oligomer Tau (TOC1)

Merge
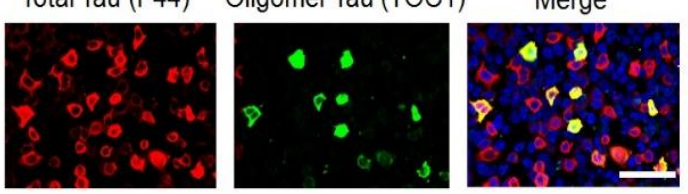

Pioglitazone
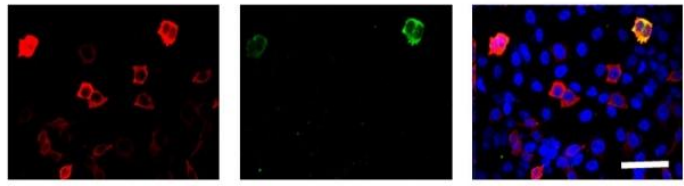
Fig. 4.

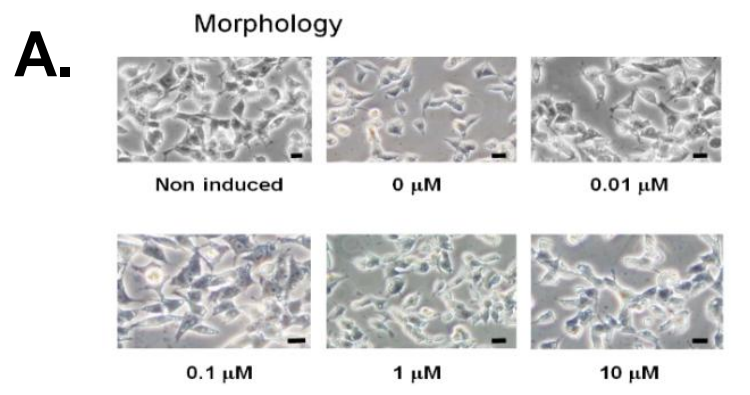

C.
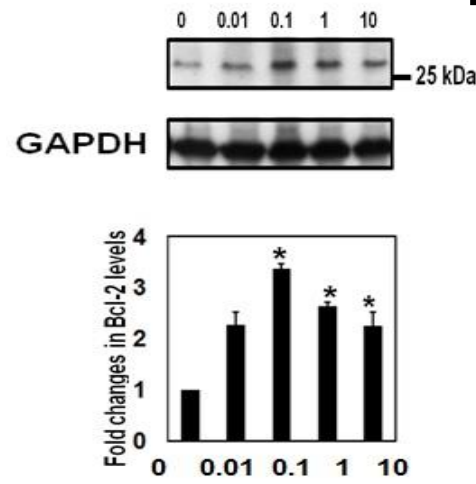

D. Cleaved caspase3

$\begin{array}{lllll}0 & 0.01 & 0.1 & 1 & 10\end{array}$

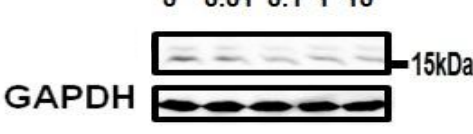

B.

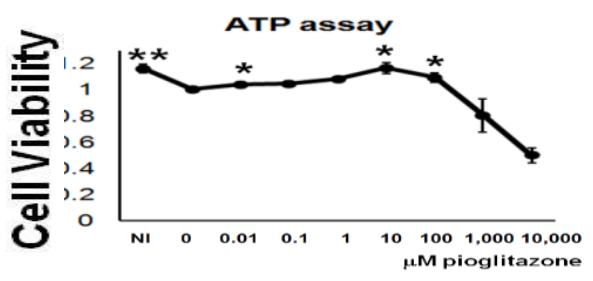

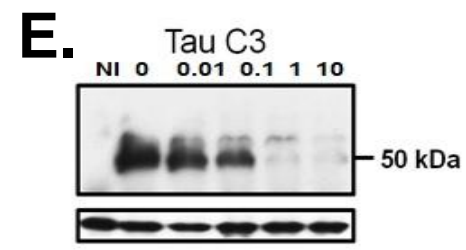
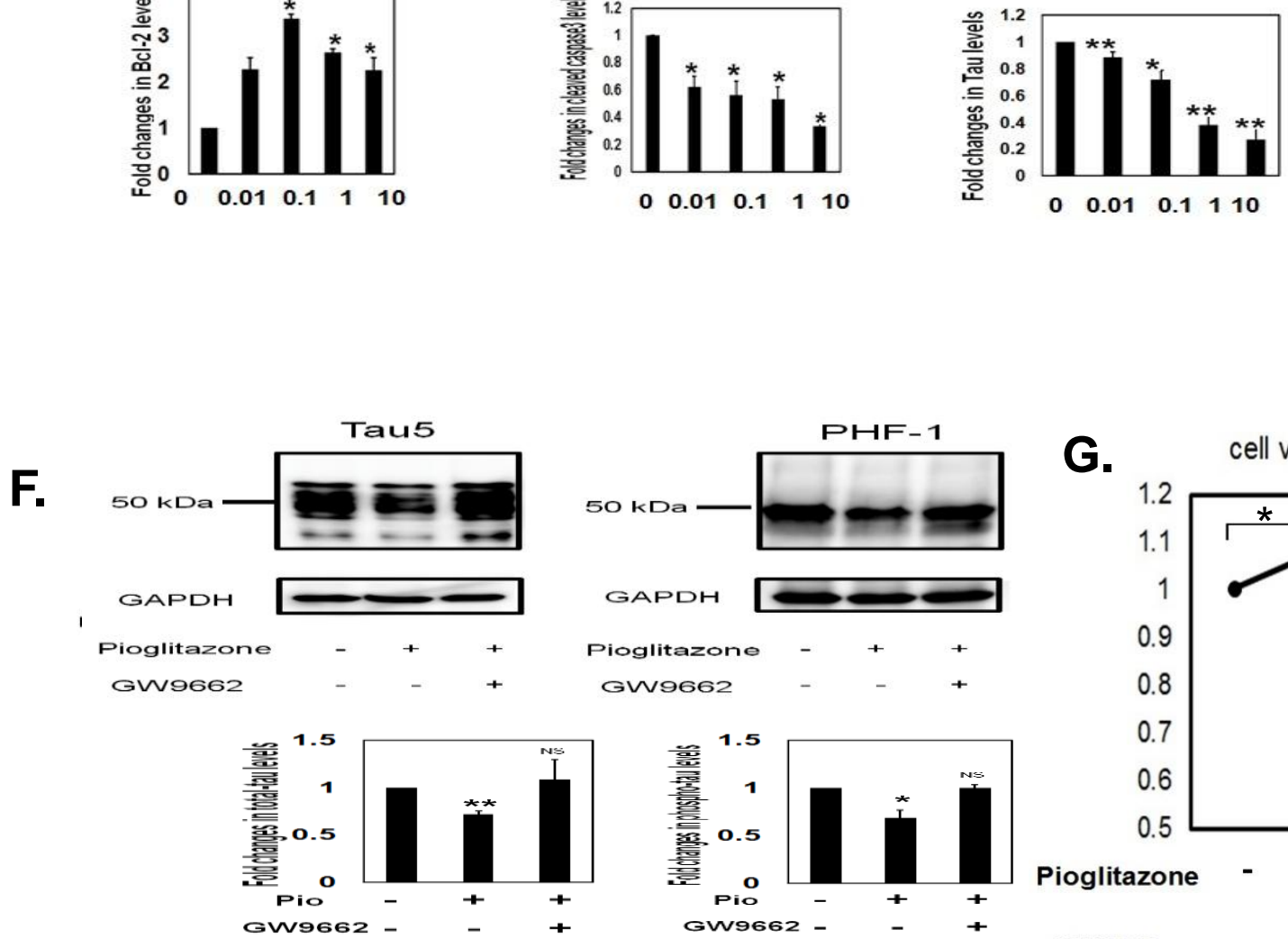

G. cell viability

Pioglitazone - + +

GW9662 -

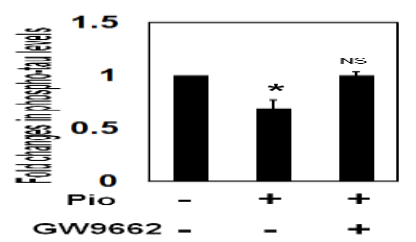

Pioglitazone - $+\quad+$ GW9662 